\title{
Strategies for achieving the fourth and fifth millenium development goals in Nigeria: Nursing perspective
}

\author{
Akinwaare Margaret Omowaleola \\ Department of Nursing, College of Medicine, University of Ibadan, Oyo State, Nigeria. \\ Accepted 29th July, 2013

\begin{abstract}
Nigeria as a signatory to the Millennium Development Goals (MDGs) declaration has been making concerted effort to actualize these human development goals. She has put some strategies in place to specifically address the issue of health-related MDGs, especially MDGs 4 and 5 . This paper therefore, reviewed some of the strategies put in place in order to achieve the fourth and fifth MDGs in Nigeria.
\end{abstract}

Key words: Millennium Development Goals (MDGs), Nigeria, health-related MDGs

\section{INTRODUCTION}

The turn of the last century ushered in a new millennium - a millennium with its hopes, aspirations and fears for its billions of inhabitants. Towards the end of the last century, various far-reaching agreements were made at the numerous conferences of the United Nations with its collaborating agencies. The enormous burden of poverty, hunger, ill-health, environmental degradation and natural disease posed significant threat to peace, stability and hence continued human existence (Kofi Annan, 2006).

In September, 2000, the world witnessed the largestever gathering of Heads of State. This gathering, tagged the United Nations (UN) Millennium Summit in New York, USA, and endorsed the UN millennium declaration which was endorsed by the 189 countries including Nigeria. The declaration was then translated into a roadmap, setting out goals to be reached by 2015 (Ladipo, 2005).

\section{THE MILLENNIUM DEVELOPMENT GOALS (MDGs)}

The MDGs are a series of eight time-bound development goals that seek to address issues of poverty, education, equality, health and environment, to be achieved by the year 2015 (World Health Organization (WHO), 2000).
They are: to eradicate extreme hunger and poverty; to achieve universal primary education; to promote gender equality and empower women; to reduce child mortality; to improve maternal health; to combat human immunodeficiency syndrome/acquired immune deficiency syndrome (HIV/AIDS), malaria and other diseases; to ensure environmental sustainability, as well as to develop a global partnership for development.

Demonstrating Nigeria's commitment to the MDGs, former President Olusegun Obasanjo launched the National Economic Empowerment Development Strategy (NEEDS), a comprehensive socio-economic reform compact, which incorporates the MDGs. A presidential committee on the MDGs that will guide the nation towards their achievements was also created, and a Senior Special Assistance to the President on Millennium Development Goals (SSAP-MDGs) was appointed. The office of the SSAP-MDGs functions as secretariat to the presidential committee, and is responsible for establishing a Virtual Poverty Fund (VPF), which will house debt relief gains for MDG related expenditure.

Also in 2007, Late former President Umaru Musa Yar'adua launched a seven-point agenda with the MDGs at its centre, further reinforcing the government 
commitment to eliminating poverty.

\section{Millennium development goals 4 and 5}

The fourth goal which is to reduce child mortality by twothirds by the year 2015, can only be achieved if the mothers are alive, healthy and knowledgeable (Ndikom, 2010). Health of the newborn infant is known to be related to the health of the mother. World leaders at the United Nations Millennium Summit in September, 2000 agreed on a critical goal to reduce deaths of children under 5 years by two thirds, but this may be unattainable without halving newborn deaths, which now comprise $40 \%$ of all under-5 deaths (National MDGs Report, 2004).

The fifth MDG is to reduce maternal mortality ratio (MMR) by three-quarters by the year 2015 . The indicators include MMR and proportion of births attended by skilled health professionals (National MDGs Report, 2004). In other words, the targets for this fifth MDG are; firstly to reduce by three quarters the maternal mortality ratio by year 2015 and secondly to achieve universal access to reproductive health (Shiffman, 2004). Maternal mortality shows the greatest disparity among countries in subSaharan Africa. A woman's risk of dying from treatable or preventable complications of pregnancy and childbirth over the course of her lifetime is 1 in 22, compared to 1 in 7,300 in developed regions (United Nations, 2005). Every year, more than 1 million children are left motherless and vulnerable because of maternal death. Children who have lost their mothers are up to 10 times more likely to die prematurely than those who have not (United Nations, 2008).

\section{Health Implication}

According to Dr. Lee Jong-Wook, the former DirectorGeneral of the World Health Organisation (WHO), improvements in health are essential if progress is to be made with the other MDGs. Health and education are squarely at the centre of the MDGs. Three out of eight goals, eight out of eighteen targets and 18 out of 48 indicators relate directly to health (United Nations General Assembly, 2000). Health is also an important contributor to several other goals. The cross-sectoral nature of health determinants has long been known. This knowledge has more comprehensive approach of health being addressed within a broad economic and political framework. This is why public health professionals have long advocated to be at the centre of policy development of the government (WHO, 2002). This, the MDGs have tried to achieve.

The direct health implication of MDGs 4 and 5 as indicated by the state of reproductive health indices in developing countries continue to send shock waves across the globe. Various efforts to date are yet to yield any significant dividend. Instead, the indices seem to even worsen. It is believed that infant and maternal mortality rates are among the best indicators of social development anywhere (Society of Gynaecology and Obstetrics of Nigeria (SOGON), 2004). But in Nigeria, the health indicator as revealed by the Nigeria Demographic Health Survey (NDHS) (2008) reported a significant decrease in maternal and child mortality.

\section{SITUATION ANALYSIS IN NIGERIA}

\section{Health indicator}

This is according to the Nigeria Demographic Health Survey (NDHS) (2008).

\section{Childhood mortality}

Childhood mortality is decreasing in Nigeria. Currently, 75 children per 1,000 live births die before their first birthday (40 per 1,000 before the age of one month and 35 per 1,000 between one and twelve months). Overall, 157 children per 1,000 live births, or about 1 child out of 6 die before reaching age five. Infant mortality has dropped $25 \%$, from 99 deaths per 1,000 live births in 2003, and child mortality has also fallen slightly from 97 in 2003 to 88 in 2008. Mortality rates differ by residence. The underfive mortality rate for the 10-year period before the survey in urban areas is 121 deaths per 1,000 live births compared to 191 in rural areas. Under-five mortality ranges from 89 deaths per 1,000 live births in the South West zone to 222 in the North East zone. As expected, childhood mortality drops with mother's education. Children of mothers with no education are two to three times more likely to die before age five than those whose mothers have more than secondary education. Childhood mortality also decreases as household wealth increases. Recent interventions - including Integrated Management of Childhood Illnesses - that reflect the underlying causes of child deaths, have contributed to these successes. However, these need to be rapidly expanded and accelerated if Nigeria is to achieve Goal 4. Access to primary health care needs to be improved by more investment in infrastructure, human resources, equipment and consumables, and better management. Implementation arrangements must target local needs, which vary hugely from community to community and state to state. Routine immunisation is unsatisfactory but can be rapidly improved by building on the successes of the neareradication of polio.

\section{Maternal mortality}

The maternal mortality ratio in Nigeria is estimated to be 545 deaths per 100,000 live births. Recent progress towards this Goal is promising and, if the latest 
improvements can be sustained at the same rate, Nigeria will reach the target by 2015 . Maternal mortality fell by 32 per cent, from 800 deaths per 100,000 live births in 2003 (at the time one of the highest maternal mortality rates in the world) to 545 deaths per 100,000 live births in 2008 . However, the proportion of births attended by a skilled health worker has remained low and threatens to hold back further progress. Government commitment is not in doubt. An innovative Midwives Service Scheme is expected to contribute substantially to ongoing shortfalls. If the scheme is expanded in proportion to the national gap in the number of midwives, this will further accelerate progress. In addition, more mothers will be covered by antenatal care as access to quality primary healthcare improves and incentives attract health workers to rural areas, indicating that Nigeria will turn progress to date on this goal into a MDG success story (Figures 1 to 3 ).

\section{STRATEGIES FOR ACHIEVING 4TH AND 5TH MDGS IN NIGERIA}

In a bid to improve the situation analysis in Nigeria as revealed by the preceding account of the existing health indicators, as well as in her commitment to achieving the MDGs 4 and 5, Nigeria has put in place some programmes such as; National Health Insurance Scheme (NHIS); Health Sector Reforms (HSR); introduction of Midwifery Service Scheme (MSS).

\section{National health insurance scheme}

What is known today as NHIS was conceptualized by Dr. Moses Majekodunmi, the then Federal Minister of Health in 1962. He brought the concept into the attention of the Federal government (Ferreira, 2009). During the 1st republic, the scheme was made compulsory for public service workers. Meanwhile, the scheme was obstructed following the Nigerian civil war which affected the programme for many years (Agba et al., 2010).

In 1984, the Nigeria Health Council under the Buhari Administration resuscitated the NHIS and a committee was set up to look at the scheme. In 1988, the then Minister of Health, Professor Olukoye Ransome Kuti commissioned the Eronmi-led committee, who submitted her report which was approved by the Federal Executive Council in 1989 (Agba et al., 2010). Consultants from International Labour Organisation (ILO) and the United Nations Development Programme (UNDP) carried out feasibility studies and came up with the cost implication, draft legislature and guidelines for the scheme which was approved by the Federal government and directives were issued to the Federal Ministry of Health to start the scheme in the country in 1993 (Adesina, 2009).

In 1999, the scheme was modified to cover more people via Decree No.35 of May 10, 1999 which was promulgated by the then Head of State, Gen. Abdulsalami Abubakar (Adesina, 2009). The programme was further expanded via legislative provision in 2004 and finally launched in 2005.

The specific objectives of NHIS include: to provide universal health care in Nigeria; to control/reduce arbitrary increase in the cost of health care services in Nigeria; to protect families from high cost of medical bills; to ensure equality in the distribution of health care service cost across income groups; to ensure high standard of healthcare delivery to benefactor of the scheme; to boost private sector participation in health care delivery in Nigeria; to ensure adequate and equitable distribution in health care facilities within the country as well as to ensure that primary, secondary and tertiary health care providers are equitably patronized in the federation.

In order to ensure achievements of these objectives, various programmes were developed, such as; formal sector social health insurance programme, children under-five social health insurance programme, urban self-employed social health insurance programme and rural community social health insurance programme. Presently, according to NHIS director - Dr. Dogo Mohamed, the scheme has been upgraded to adequately take care of the goals 4 and 5 of the MDGs. According to Honourable Minister of Health - Professor Onyebuchi Chukwu, the scheme covers six million Nigerians presently, as compared with three million in 2011 and hope to cover all Nigerians by 2015.

\section{Health sector reform}

Health sector reform has been described as a broadbased purposeful and sustainable fundamental change system (that is, vision, policies, legislations institutional arrangement, organization, plans, programmes and projects) in order to deliver efficient, quality, affordable, accessible, effective and equitable health care services to the populace and ultimately improve the health status of the people (Federal Ministry of Health (FMOH), 2004). Seven strategic pillars of the Health Sector Reforms are: defining the stewardship roles of the three tiers of government; strengthening the natural service delivery system and its management; reducing the disease burden due to priority health problems; ensuring adequate health resources are available and better management system are put in place; improving access to quality health services; enhancing consumers' awareness and community improvement in health; promoting effective partnership and condition.

The Health Sector Reform (HSR) process provides a fundamental shift in how we think about health, how its services are delivered and what each of our roles and responsibilities are in providing better health for all Nigerians. There are clear benefits for all Nigerians with the new priorities identified in the Bill and the revised policy. The benefits include: better quality health services that are better organized and linked with a functional and sustainable system; health services will be available, 


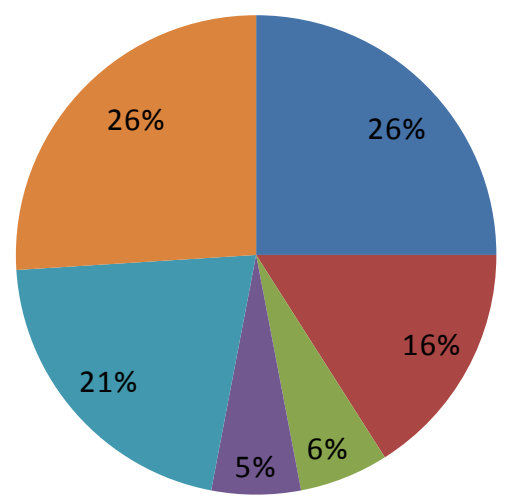

Figure 1. Major causes of under five mortality.

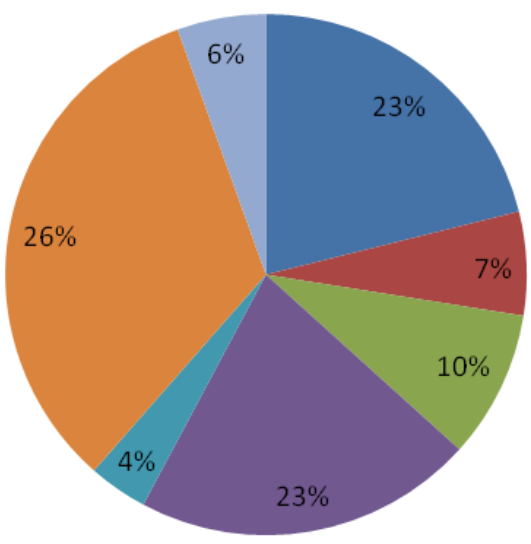

Figure 2. Neonatal causes.

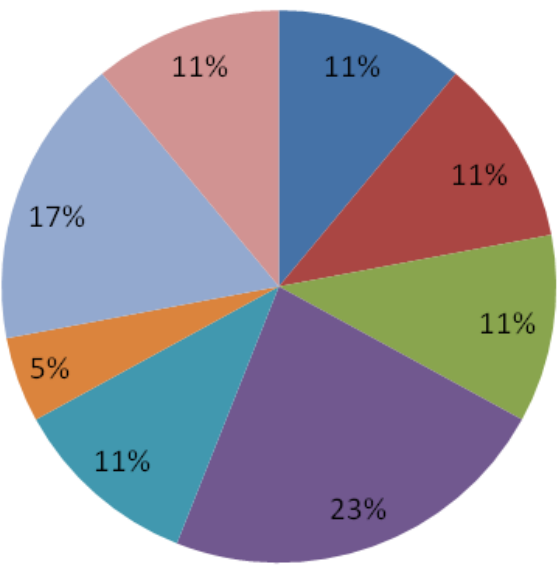

Figure 3. Major causes of maternal mortality. malaria

diarrhea

measles

HIV

pneumonia

neonatal causes
- Preterm birth

congenital

- Tetanus

- Severe infection

- Diarrhoea disease

Birth Asphyxia

others
Obstructed labour

Anaemia

Puerperal infection

- Haemorrhage

- Complicated abortion

Eclampsia

Others

- Malaria acceptable and accessible from a wide variety of public and private health providers; managers will have more evidence-based budgeting and will be able to manage their systems more effectively; providers will have further training to be more responsive to users; accelerated promotion of key family practice to create demand and develop advocacy messages towards improving maternal, neonatal and child health as well as universal access to effective family planning information and services to all Nigerians. 
Over the years, several initiatives and instruments have been introduced to reduce morbidity and mortality among mothers and the children. These include: Integrated Management of Childhood Illness (IMCl) strategy, Integrated Maternal Newborn and Child Health (IDSR), Integrated Disease Surveillance and Response (IDSR), intense capacity building for health workers and Community Resource Person (CORPs), accelerated child survival and development strategic framework and plan of action (2005 to 2009) to guide the implementation of child and maternal survival intervention by government at all levels. These interventions have proved efficient in the achievement of MDGs 4 and 5. However, despite these interventions, gaps still exist. These gaps range from infrastructure, to access to services, out of pocket expenses and human resource needs for all levels of care.

\section{Introduction of midwifery service scheme (MSS)}

The first meeting between the Federal Ministry of Health and the special adviser to Mr. President on Maternal and Child Health which was chaired by the then Honourable Minister of Health, Professor Eyitayo lambo brought about the Midwifery Service Scheme (MSS). The MSS was set to address the human resource needs for skilled attendants at the primary level of care (Ugo, 2010).

Specific objectives of MSS were: to increase proportion of pregnant women receiving antenatal care from 60 to $80 \%$; to improve proportion of deliveries attended to by skilled birth attendants from 36.3 to $72.6 \%$; to reduce maternal mortality from 800 to 25 per 100,000 live birth; to reduce the incidence of low birth weight from 14.5 to $10 \%$; to reduce neonatal mortality from 48 to 18 per 1000 live birth; to expand utilization coverage of family planning services from 13 to $50 \%$; to increase by $70 \%$ the proportion of primary health care facilities manned by qualified midwives; to increase by $35 \%$ the proportion of primary health care facilities providing essential/ emergency obstetric care (BEOC); to ensure that all recruited midwives are trained on Life Saving Skill (LSS) and $\mathrm{IMCl}$ as well as to build effective partnership between community based institutions and facility based health providers in all targeted communities.

\section{Expected outcome of MSS}

The expected outcome of MSS is that maternal and neonatal mortality will be reduced in line with the MDGs 4 and 5 . To be able achieve this, basic midwifery training programme was re-introduced.

\section{Re-introduction of basic midwifery training programme}

The high maternal and child mortality and morbidity rate has been linked to shortage of skilled personnel to attend to women during delivery particularly in the rural communities (World Health Organization (WHO), 2006). In response to this problem, the Nursing and Midwifery Council of Nigeria (N\&MCN) in 2003 re-introduced the basic midwifery training programme. The programme is designed to prepare competent, skilled and versatile midwifery practitioners who are capable of providing high level care settings communities, in order to reduce maternal and infant mortality rate. The objectives include: to assess the basic health needs of a community and intervene appropriately; to utilize the nursing process in providing comprehensive nursing and midwifery care to individuals and groups in the community and in all primary health care settings; to identify risk factors obstetrics and take appropriate action; to function independently and in collaboration with other members of the Health team and related sectors; to practise safe and clean delivery services; to supervise the clinical experience of student midwifes and paramedical personnel in the community; to network with the government and nongovernment organizations to address youth reproductive health problems; educate individuals, families and groups in order to effect change in the reproduction pattern of the community; to utilize appropriate clinical protocol in managing obstetrics emergencies and refer them appropriately to save lives of mother and child; to utilize the knowledge and skills of information, education and communication in improving reproductive health care services; to collaborate with the community to improve the reproductive health status of women, youth and men.

\section{Strengths of the basic midwifery programme}

At the re-introduction of the basic midwifery programme in the country, 17 states chose to run the programme with 22 schools ( 16 schools owned by the government while 6 were owned by voluntary agencies). The first batch of students graduated in March, 2006. With this special education, a midwife is capable of functioning in all areas including primary health care setting. She is also able to make independent judgement, manage normal midwifery, provide appropriate care including family planning and refer individuals with high-risk pregnancies and complications to other levels of health care. The expected result of this programme is that there will be reduction in maternal and mortality in line with the MDGs 4 and 5.

\section{Outcome of the programme so far}

As of 2010, 2,622 midwives have been deployed to Primary Health Care (PHC) facilities in rural areas. MSS provided capacity building by the creation of a training framework, which was aimed at improving the skills and proficiency of midwives in provision of quality maternal and child health services. According to Dr. Parte- 
Director, National Primary Health Care Development Agency (NPHCDA) - monthly reports indicate improvement in antenatal attendance and delivery by skilled birth attendants in the target facilities. The NPHCDA identified information and communication technology (ICT) connectivity and application of global system of mobile communication (GSM) technology as a potential strategy that could enhance the effective implementation and management of the system. The ICT connectivity has facilitated provision of dedicated voice communication system to connect the midwives and other health workers to support centres at the headquarters and data transmission.

\section{ROLES OF NURSING IN ACHIEVING THE 4TH AND 5TH MDGS IN NIGERIA}

Nursing has been recognised to be at the centre or the focus of achieving the MDGs 4 and 5 through the provision of evidence-based interventions which has identified three healthcare service delivery modes namely:

\section{Family oriented community based services}

These include clean delivery and core care, putting baby to breast within 30 min of delivery, temperature management, use of insecticide treated net (ITN) by under-5 children, antimalarial treatment, use of portable drinking water, oral rehydration therapy, exclusive breastfeeding for children 0 to 5 months, supplementary and therapeutic feeding for malnourished children.

\section{Population oriented outreach and schedulable services}

These are tetanus immunization, prevention and treatment of anaemia in pregnancy and antenatal care.

\section{Individually oriented clinical services}

These include resuscitation of asphyctic newborn, manage-ment of neonatal infections at primary health care level, artemisinin-combination therapy for children and treatment of pneumonia with antibiotics for under-5 children. Also, through midwives, pregnant women have adequate information and support to control their reproductive health, they also receive help and care which is available throughout pregnancy, childbirth and newborn childhood at the community level. In addition, communities are linked to the formal health sector by the adoption of culturally-sensitive approaches that allow the midwife to apply her basic knowledge of cultural norms surrounding sexuality and the childbearing practices of the women to build the needed community trust in her services (Jemima, 2010). Furthermore, essential adole- scent sexual and reproductive health services are made available at the primary health care levels, family planning services are brought to the doorstep of the community and midwives also play an important role in post-abortion care through identification and referral of women with complications from unsafe abortion.

\section{Challenges of achieving the MDGs 4 and 5}

While acknowledging the MDGs as a worthy step in the right direction, some glaring drawbacks need highlighting.

\section{The MDGs say nothing about strengthening health system}

According to $\mathrm{WHO}$, building up and strengthening health system is vital if more progress is to made towards the MDGs (Travis et al., 2004). In the absence of adequate resources, achieving MDGs 4 and 5 remains a challenge.

\section{The tactful but subtle exclusion of sexual and reproductive health (SRH) from the MDGs is inappropriate}

Though reduction of maternal mortality in MDGs is an aspect of $\mathrm{SRH}$, an all embracing inclusion would have been more apt as appropriately highlighted by the international Conference on Population and Development (ICPD) in Cairo in 1995. The reduction of poverty, maternal and child mortality and HIV/AIDS spread are integral affirmation of the ICPD declaration on SRH. A strong commitment to $\mathrm{SRH}$ is essential for achieving the MDGs 4 and 5.

\section{No adequate budgetary plan}

There are no specific set standards on budgetary imperative for the attainment of the MDGs 4 and 5 , as well as problem in fulfilling the signed memorandum of understandings by States and Local Governments areas. There are also difficulties in relocation of midwives to the rural areas, as well as the Northern Zones of Nigeria.

\section{CONCLUSION}

It must be noted that there has been preceding discrepancy between the setting of international goals and the interpretation and implementation of policies and programmes that truly address the needs of individuals and families in the various countries. The MDGs represents a concerted effort by the global community to focus attention, resources and action on improving the wellbeing of all people(Wolfensohn, 2004). Two of the goals, 
(MDGs 4 and 5) were set to reduce the childhood mortality rate and maternal mortality ratio, by two-thirds and three-quarters, respectively from 1990 to 2015. These goals are clearly achievable and have been described as the minimum goals required for meaningful development and stability (Jeffrey and wolfenson, 2004).

However, there is need for nurses to be aware of their roles in the achievement of MDGs 4 and 5. Also, there is need for collaboration between the academic and clinical nurses to work towards the achievement of these goals. In addition, further collaboration is required among all stakeholders in maternal and child health; including health professionals (especially midwives), the government and the non-governmental organisations to ensure the achievement of these goals.

\section{REFERENCES}

Adesina, D (2009). The National Health Insurance Scheme. Retrieved October 3 from http://www.nigeriandoctor.com?news.php?extend. 85D.

Agba, A.M, Ushie, E.M, and Osuchukwu, N.C, (2010). National Health Insurance Scheme and Employees' Access to Healthcare Services in Cross River State, Nigeria. Global Journal of Human Social Science.

Ferreira, A, (2009). Use The NHIS to Develop Access to Organised Health Care Service. Available at http://www.nigeriavillagesquare.com?articles.

FMOH (2004). Federal Republic of Nigeria; Revised National Health Policy, Federal Ministry of Health, Abuja. September, 2004 for struggle, Solidarity and Socialism in Nigeria Health Insurance Scheme Abuja, Nigeria.

Jeffrey DS (2004). Health in the Developing Countries: Achieving the Millennium Development Goals. Bulletin of the world Health Organisation.82(12).

Jemima D (2010).Achievement of MDGs 4, $5 \& 6$. The role of the midwife. West Afr. J. Nurs. 21 (1):100.

Kofi Annan (2006). United nations' Secretary General's Message for the New Millenium Available at http://ww.unorg/millennium/sg/report. accessed 9 June, 2011.

Ladipo OA (2005). The Cairo consensus and Millennium Development Goals: Reality or mirage- The Second Olusola adewale Ojo memorial oration. Trop. J. Obstet Gynaecol. 22(2):89-99.
National MDGs Report 2004. Millennium Development Goals. Report 2004. Nigeria.

Ndikom C (2010). Prevention of Perinatal Infection in the Achievement of MDGs 4 and 5. Afr. J. Nurs. Health Issues. 1(2):104-105.

Shiffman J (2004). Generating Political Priority for Safe Motherhood. Afr. J. Rep. Health. 8(3):6-10.

Society of gynaecology and Obstetric of Nigeria. Communiqué from the $38^{\text {th }}$ Annual Scientific Conference of SOGOn ( 2004 ). Trop. J. Obstet Gynaecol. 22(1): 100.

Travis P, Benett S, Haines A, Pang T, Bhutta Z, Hyder N (2004). Overcoming Health - systems constraint to achieve the MDGs. Lancet. 364(9437):900-6.

Ugo Okoli (2010). Tackling Maternal Mortality using the National Midwifery Scheme. Presentation at the $22^{\text {nd }}$ Nigeria Partnership for Health Conference.

United Nations (2008). The Millennium Development Goals Report 2008. GOAL 5: Improve maternal health. High-level Event on the Millennium Development Goals, United Nations Headquarters, New York. Available at www.un.org/millenniumgoals.

United Nations General Assembly (2000). United nations Millennium Development Declaration. Resolution 55/2. Available at http://www.un.org/millennium/declaration/area. 552epdf. Assessed 9 June, 2011.

United Nations (2005). The Millennium Development Goals Report. Available at http://www.un.org/milleniumgoals. Assessed 9 June, 2011.

Wolfensohn J (2004). Speech by the president of the world Bank James Wolfensohn at a conference on'Making Globalization work for all the challenge of delivering the Millennium Development Goals. Available at http://www.hm - treasury.gov.uk. Assessed 9 June, 2011.

World Health Organisation (2006). Measuring Progress towads health in the mellenium Development Goals. Available at www.who.int/mdg. assessed 9\.2011. 